\title{
The single-celled ancestors of animals: a history of hypotheses
}

Thibaut Brunet and Nicole King

Howard Hughes Medical Institute and the Department of Molecular and Cell Biology, University of California, Berkeley, CA, United States

For correspondence: t.brunet@,berkeley.edu,nicoleking.ucb@gmail.com

\begin{abstract}
Animals, with their complex and obligate multicellularity, evolved from microbial eukaryotes that were likely obligately or facultatively unicellular. The nature of the unicellular progenitors of animals has intrigued biologists since the late $19^{\text {th }}$ century, coinciding with the parallel spread of the cell theory and the theory of evolution. However, views on the ancestry of animals have been extremely varied. The huge diversity of single-celled organisms, the tremendous plasticity of animal cellular phenotypes, and the difficulties of organizing both into clear phylogenies in the pre-molecular era allowed a wide range of hypotheses to flourish, with nearly every major single-celled lineage, at one time or another, having been proposed as the precursor of animals (Table 1). Most of these hypotheses never gained followers beyond their originator (such as the ideas that animals evolved directly from either bacteria, Volvox or fungi) and will not be discussed here (see Table 1). Three concepts, however, have been enduring and influential: (1) the amoeboid theory; (2) the flagellate theory; and the (3) the ciliate theory - to which a fourth category can now be added: (4) a mixed model, in which the ancestor was phenotypically plastic. We will discuss their origin, history, and current relevance.
\end{abstract}

Keywords: evolutionary cell biology; evo-devo; animal origins; choanoflagellates; history of science; Haeckel; Metchnikoff; Blastaea; origin of multicellularity 


\section{Origin of the question: the cell theory and the concept of common descent}

The question of the single-celled ancestor of animals only makes sense in the light of two concepts that are now central to biology and that emerged in parallel in the second half of the $19^{\text {th }}$ century: (1) the cell theory, which posits that all living beings are composed of cells (some of many, some of only one) (Schleiden 1839; Schwann 1839); and (2) the theory of common descent, which posits that all living species - unicellular or multicellular - descended from a single common ancestor (Darwin and Wallace 1858).

That all living beings are made of cells is the first fact many of us learned about biology, and is so familiar that we sometimes take it for granted. But the cellular organization of all life forms was not initially obvious, and it took a full 250 years after the invention of the microscope for this idea to gain general acceptance. Two of the first people to observe microorganisms (van Leeuwenhoek 1677; Müller 1786) indiscriminately used the terms "infusorians" or "animalcules" to describe what we now think was a mélange of unicellular

Table 1. Timeline of hypotheses on the single-celled precursor of animals

\begin{tabular}{|c|c|c|}
\hline Nature of the hypothesized ancestor & Proposed as early as & References \\
\hline Amoeba & 1876 & $\begin{array}{c}\text { (Haeckel 1876, 1914; } \\
\text { Hanson 1977; Reutterer } \\
\text { 1969) }\end{array}$ \\
\hline Ciliate & 1882 & $\begin{array}{c}\text { (Hadzi 1953, 1963; } \\
\text { Hanson 1963, 1977; Kent } \\
\text { 1882; Sedgwick 1895; } \\
\text { Steinböck 1963) }\end{array}$ \\
\hline Flagellate & 1884 & $\begin{array}{l}\text { (Brunet and King 2017; } \\
\text { Bütschli 1884; Cavalier- } \\
\text { Smith 2017; King 2004; } \\
\text { Metchnikoff 1886; } \\
\text { Nielsen 2008; Nielsen } \\
\text { and Norrevang 1985) }\end{array}$ \\
\hline Fucus-like syncytial brown alga & 1924 & (Franz 1924) \\
\hline Amoeboflagellate or complex ancestor & 1949 & $\begin{array}{l}\text { (Arendt et al. 2015; } \\
\text { Brunet et al. 2020; } \\
\text { Mikhailov et al. 2009; } \\
\text { Sachwatkin 1956; Sebé- } \\
\text { Pedrós, Degnan, and } \\
\text { Ruiz-Trillo 2017; } \\
\text { Willmer 1971; } \\
\text { Zakhvatkin 1949) }\end{array}$ \\
\hline Volvox-like alga & 1953 & (Hardy 1953) \\
\hline Prokaryote & 1974 & (Pflug 1974) \\
\hline
\end{tabular}




\section{3}

protists (e.g. ciliates, heliozoans, amoebae, and flagellates) and small multicellular animals (e.g. rotifers and flatworms). Multicellular organization was first described in 1665 by Robert Hooke based on his observations of dead plant tissue in the form of a bottle cork. Hooke was intrigued by the structures he was later to name "cells," but had no idea he had discovered a general phenomenon, and considered them a structural peculiarity of cork. An additional 170 years of research and many additional observations were needed before the official "birth date" of the cell theory, often attributed to Schwann (1838) and Schleiden (1839) (reviewed in (Morange 2016). Once the cell theory was accepted, several early cell biologists (including Meyen (1839), Dujardin (1841), Barry (1843) and von Siebold (1845)) took the leap to posit that the simplest life forms might consist of only one cell (reviewed in (Leadbeater and McCready 2002)).

The theory of evolution emerged in parallel with the cell theory. The first elaborate theory of evolution, proposed in 1809 by the French biologist Jean-Baptiste de Lamarck (17441829), assumed that life started with the spontaneous generation of "infusorians"- including both protists and small animals (Lamarck 1809). Infusorians were then inferred to have gradually evolved into all other organisms through a progressive increase in size and complexity, with no individual step that would have clearly paralleled our modern concept of a transition to multicellularity. Lamarck's ideas attracted attention and criticism, but the concept of common descent did not become widely accepted until after the debate spurred by the theory of evolution through natural selection proposed by Charles Darwin (1809-1882) and Alfred Russel Wallace (1823-1913) (Darwin 1859; Darwin and Wallace 1858). Their theory was the first to propose a plausible mechanism for descent with modification, and thus brought new credibility to the concept of evolution.

By the end of the $19^{\text {th }}$ century, the scientific stage was set for considering the origin of animals: both evolution and cell theory had gained widespread acceptance, and three of the most abundant and charismatic groups of single-celled organisms had been identified - flagellates, ciliates and amoebae (Table 1). Quickly, all three were considered as potential ancestors of animals. 


\section{Haeckel's hypothesis: amoebae as ancestors}

The first researcher to attempt to reconstruct the unicellular progenitor of animals was the German biologist Ernst Haeckel (1834-1919), arguably one of Darwin's most high-profile supporters in continental Europe (Richards 2008). While Haeckel's name is most often mentioned today in the context of his now-obsolete theory of recapitulation (according to which development directly recapitulated evolution (Gould 1977)) or for his controversial drawings of vertebrate embryos (Pennisi 1997; Richards 2009), his contributions to biology were much broader, and one can get an idea of their scope by considering that he coined the words “ecology", "ontogeny", "phylogeny”, and "gastrulation” among many others.

Haeckel had an exceptionally ambitious research program: organizing all of life's diversity into a phylogenetic framework and - if that was not enough - reconstituting the extinct ancestors that occupied the most important nodes of that tree. In his attempt to reconstitute the single-celled progenitor of animals, he inferred it was an amoeba based on two independent sources of evidence: (1) his theory of recapitulation; and (2) Magosphaera planula, a mysterious organism that he considered the "missing link" between protists and animals.

Haeckel's case for an amoeboid ancestor started with embryology (Haeckel 1874, 1876, 1914). He noted that the egg cells of animals lack a flagellum but are often contractile.

Moreover, he observed that in sponges, the unfertilized eggs are bona fide crawling amoeboid cells (later confirmed by (Ereskovsky 2010; Franzen 1988)). After fertilization, the sponge zygote divided to give rise to a ball of non-ciliated cells (the morula) that only later acquired cilia and collectively formed an internal space (thus becoming a blastula). According to Haeckel, future feeding cavities then formed during gastrulation. Seen through a recapitulationist lens, these developmental facts told a compelling evolutionary story: animals had evolved from freeliving amoebae that had first formed balls of cells before acquiring ciliation, an internal cavity and then, eventually, evolving a gut (Haeckel 1874, 1914; Fig. 1; Box 1). Embryology might 
103 have been enough to convince Haeckel of the amoeboid origin of animals. But he felt he had

104 another critical piece of evidence: a "missing link."1
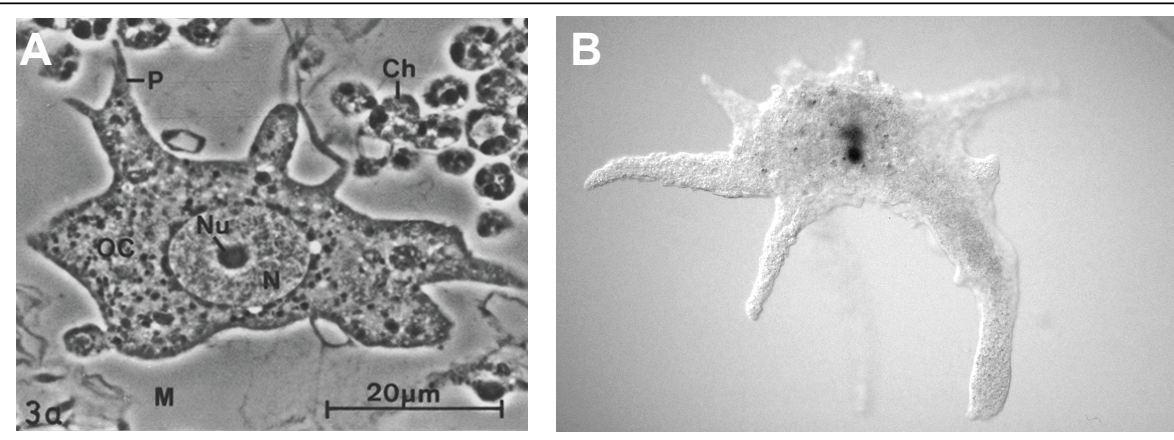

C

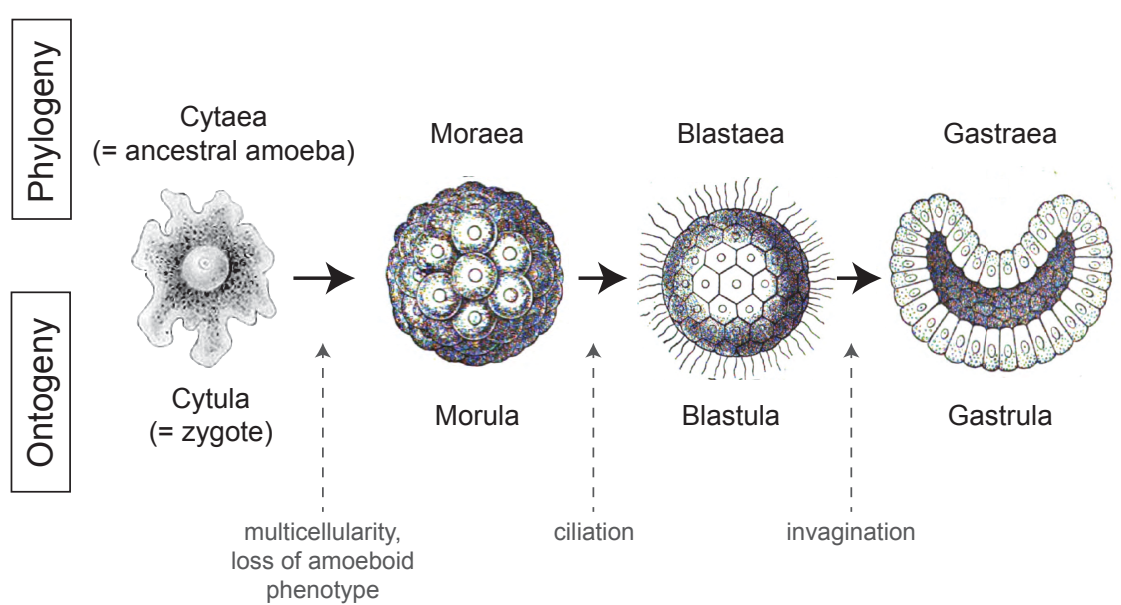

Figure 1. Haeckel's amoeboid theory of animal origins. (A) The amoeboid egg cell of a sponge (from Sycon raphanus (Franzen 1988)). (B) A free-living amoeba, Chaos carolinense (Creative Commons license; https://commons.wikimedia.org/wiki/File:Chaos_carolinense.jpg). (C) Haeckel's theory of animal origins, in which ontogeny (development) parallels phylogeny (evolution). In both courses, the starting point was depicted as an amoeboid cell, similar to the sponge oocyte and freeliving amoebae. Proliferation of such amoeboid cells was inferred to first result in the formation of a non-ciliated sphere, the Moraea/morula. Ciliation in this scenario only arose after the evolution/development of multicellularity, at the Blastaea/blastula stage. The sketch of the cytula stage is a sponge egg cell (Haeckel 1872) and sketches of the following stages are coral embryos (Haeckel 1914).

\footnotetext{
${ }^{1}$ The concept of the extant "missing link" that represent the ancestral condition is no longer considered valid, but it accurately captures Haeckel's views, which often envisioned some living groups as identical to the ancestors of other living groups.
} 


\section{Box 1: Haeckel's amoeboid hypothesis in his own words}

"The existence of this single-celled Amoeba-like primary form of the whole animal kingdom is proved by the extremely important fact that the fructified egg of all animals, of the sponge and the worm up to that of an ant and to that of man, is a simple cell. The ripe eggs of different animals frequently present very different shapes, accordingly as they may be enclosed by variously formed coverings or burdened with nutritive yolk. But the youthful egg-cells are still naked and without any membrane, of the simplest construction, and at times they even creep about in the body like an Amoeba - thus, for instance, in Sponges; they were formerly, in this case, even considered to be parasitic Amoebae." (The History of Creation, 1914, p. 149-150)

105

106

107

108

109

110

111

112

113

114

115

116

117

118

Haeckel's purported encounter with M. planula ((Haeckel 1870), reviewed in

(Reynolds and Hülsmann 2008); see also (Levit et al. 2020)) occurred in 1869 off the coast of Bergen, Norway. In a seaweed sample, Haeckel observed tiny round capsules ( $70 \mu \mathrm{m}$ large in diameter) that resembled egg cells, with a single central nucleus. These egg-like structures then started dividing at constant cell volume - like the cleavage of an early animal embryo - and gave rise to spheres of cells, each of which then acquired a covering of motile cilia. These ciliated spheres started swimming around, but did not develop further; instead, they fell to the bottom and dissociated into individual amoeboid cells that crawled around. Haeckel did not observe the further development of these amoebae but assumed they would eventually increase in volume to give rise to another spherical cell, thus completing the cycle (Haeckel 1870) (Fig. 2A).

In Haeckel's view, Magosphaera provided an important window into animal origins. Its amoeboid single-celled form matched his recapitulation-inspired view of the animal ancestor. It had facultative multicellularity, which it reached by a cleavage process similar to animal embryos. It was a concrete, living embodiment of the Moraea stage of his evolutionary timeline.

Yet, M. planula is shrouded in mystery. Haeckel saw it only once and modern efforts to re-isolate it have failed (Reynolds and Hülsmann 2008). It is an interesting exercise to take Haeckel's description at face value and wonder what he might have seen. The closest parallel to Magosphaera may be found among the ichthyosporeans, a lineage of unicellular opisthokonts closely related to animals and choanoflagellates (Fig. 2B). Ichthyosporeans are free-living amoebae or flagellates that, like Magosphaera, can grow into large round cysts that divide at constant cell volume and finally dissociate back into single cells (Suga and Ruiz-Trillo 2013). They differ from Magosphaera in three main ways: (1) the spherical multicellular form of known ichthyosporeans is never swimming or multiciliated; (2) almost all known ichthyosporeans are commensal or parasitic, not free-living; (3) the large ichthyosporean cysts are multinucleated and 


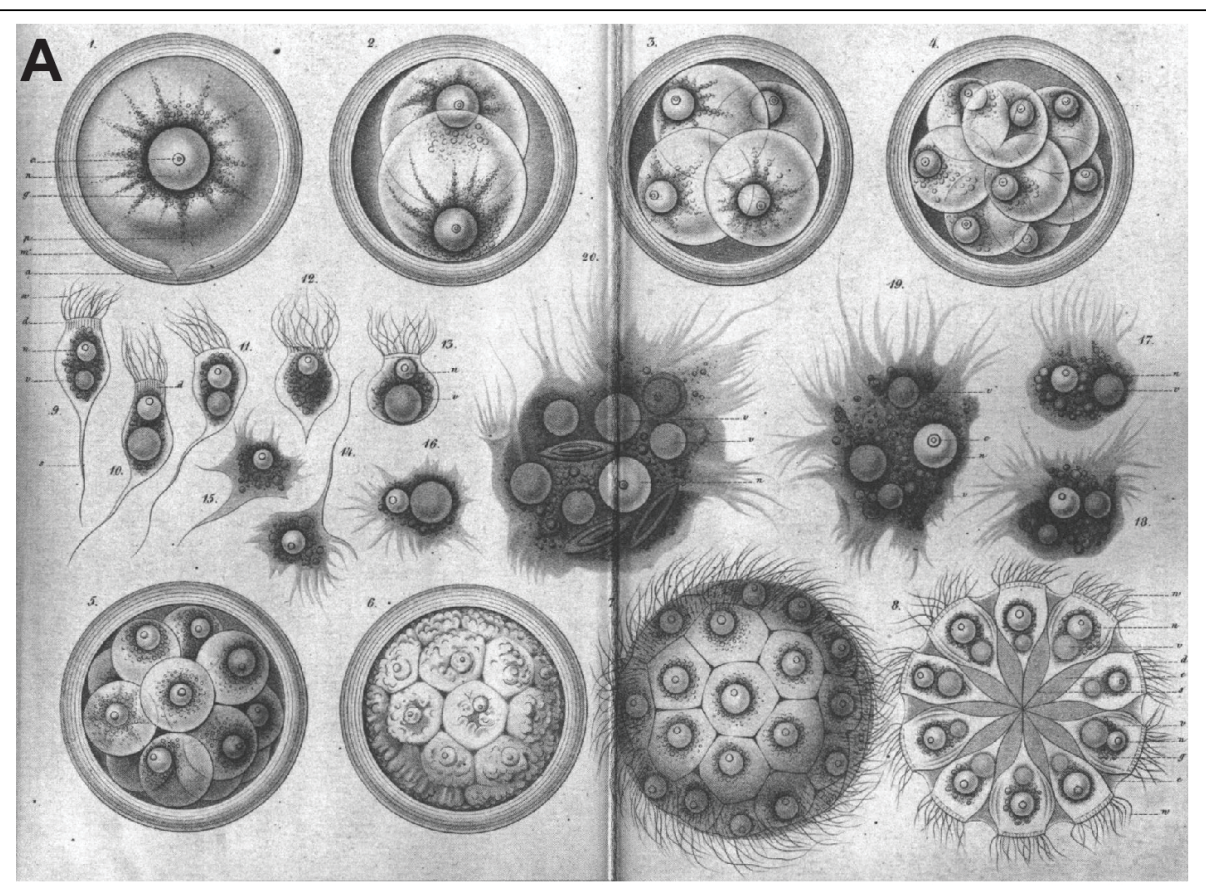

B

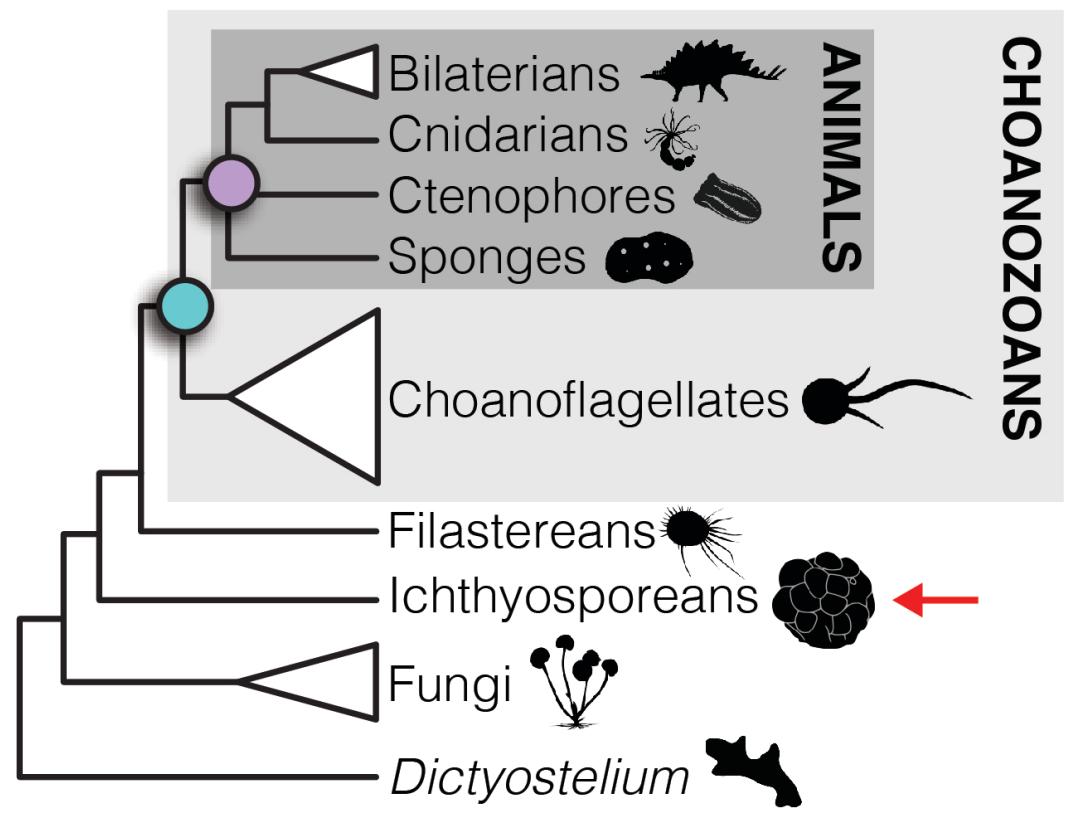

Figure 2. Mystery Organism 1: Magosphaera planula, a facultatively multicellular amoeba described by Haeckel but never re-observed, which he thought resembled the ancestor of animals. (A) Haeckel's depiction of the life history of M. planula (Haeckel 1870). The first and third row depict the cleavage of the large, spherical cell initially observed by Haeckel, resulting in a swimming sphere of multiciliated cells. The second row shows the cells produced by dissociation of that sphere, which are first multiciliated and then become amoeboid. (B) Modern phylogenetic tree showing interrelationships between animals and their closest relatives (modified from (Nichols, Dayel, and King 2009). Ichthyosporeans (red arrow) belong to a lineage considered among the closest relatives of animals and form spherical masses of spores by cleavage at constant volume, which evokes M. planula. 
divide by simultaneous global cellularization around pre-existing nuclei (Dudin et al. 2019), rather by serial binary division of a large, initially mononucleated cell (as in animal zygotes). However, an environmental metabarcoding study has suggested the existence of undescribed free-living ichthyosporeans (Del Campo and Ruiz-Trillo 2013) and three apparently free-living species have since been isolated (belonging to the genera Chromosphaera (Grau-Bové et al. 2017) and Sphaeroforma (Hassett, López, and Gradinger 2015)). If Haeckel's description was accurate, he could be the first person to have seen a free-living ichthyosporean, that would have (unlike other described ichthyosporeans) undergone serial binary cleavage from a mononucleated cyst. Alternatively, he might have misinterpreted - or exaggerated - what he saw.

For all of Haeckel's fame, his amoeboid theory never seems to have gained followers. The reasons for this are unclear, but his theory may have suffered from the rise of a worthy competitor: the flagellate theory of animal origins.

\section{Metchnikoff's hypothesis: choanoflagellates as ancestors}

Colonies of flagellates have been known since van Leeuwenhoek first observed Volvox (van Leeuwenhoek 1677). The similarity of such colonies to the blastula stage of animal development (which impressed even Haeckel (Haeckel 1914)) seemed to suggest a plausible evolutionary path from flagellates to animals - an idea that emerged shortly after Haeckel's amoeboid hypothesis of animal origins.

A first piece of evidence was the striking similarity between choanoflagellates and the feeding cells of sponges, the choanocytes. Both have a near-identical appearance with a flagellum surrounded by a ring of microvilli, together forming a "collar complex" (Brunet and King 2017) (Fig. 3A, B). This resemblance was already evident to some of the earliest choanoflagellate observers, Henry James-Clark (1826-1873) and William Saville-Kent (18451908) (James-Clark 1867; Kent 1882). Both authors erroneously concluded that sponges were specialized choanoflagellates and not animals at all. In support of his hypothesis, Saville-Kent described facultative multicellular colonies in several choanoflagellates (Kent 1882), suggesting a possible path to complex multicellularity. This idea was extended by Otto Bütschli (18481920), who suggested that sponges had evolved from choanoflagellates, while other animals had evolved from another (unidentified) flagellate group (Bütschli 1884). 

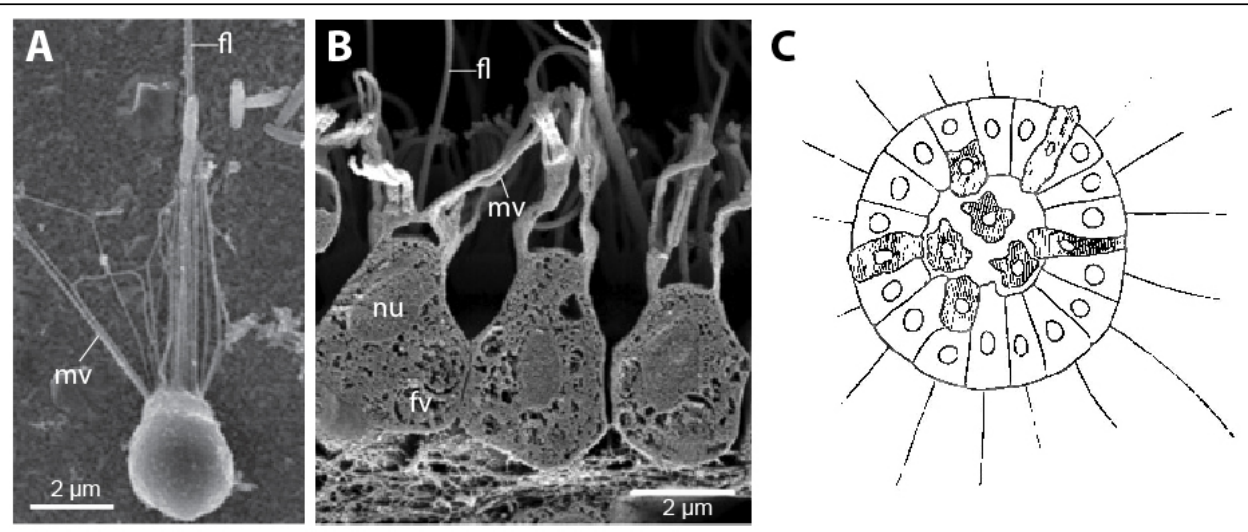

D

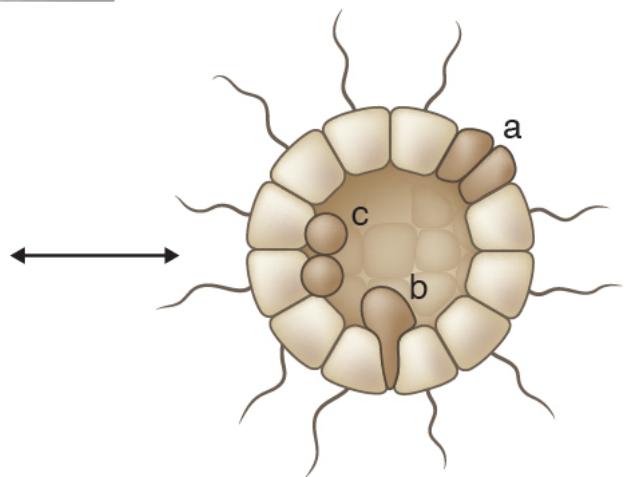

Unicellular

Colonial

Multicellular

Figure 3. The flagellate hypothesis of animal origins. (A) The choanoflagellate $S$. rosetta (Dayel et al. 2011). (B) Sponge choanocytes (Leys and Hill 2012). Note the similarity of the apical collar complex between choanoflagellates and choanocytes, composed of a flagellum (fl) surrounded by microvilli (mv). nu: nucleus, fv: food vacuole. (C) Metchnikoff's postulated flagellate colony, with some cells internalizing to balance the flagellation/motility constraint (Metchnikoff 1886). (D) A contemporary illustration of the flagellate model, redrawn after (King 2004). Cells can either divide on the surface of the colony $(a)$ or ingress inside the colony $(b)$ and divide internally $(c)$. (Drawing: Debbie Maizels)

162

163

164

165

166

167

168

169

170

The Russian biologist Elie Metchnikoff² (1845-1916; better known for having later discovered macrophages), inspired by Haeckel's inference that sponges were bona fide animals, took seriously the similarity of sponges to both choanoflagellates and to other animals. On this basis, he suggested that all animals, including sponges, might have evolved from a choanoflagellate-like ancestor (Metchnikoff 1886) ${ }^{3}$ (Fig. 3C-D; Box 2). To explain the apparent absence of collar cells in animals other than sponges, Metchnikoff suggested that the microvillous collar had been lost in these lineages, and pointed out that it is retracted in some phases of the choanoflagellate life cycle (Leadbeater 2015). (In the $20^{\text {th }}$ century, it would be

\footnotetext{
${ }^{2}$ Alternatively spelled Metschnikoff or Mechnikov.

${ }^{3}$ See (Wilson 1887) for an English translation.
} 
171

172

173

174

175

176

177

178

179

180

181

182

183

184

185

186

187

188

189

discovered that collar cells are in fact widespread in the animal kingdom and not restricted to sponges - see section $\mathrm{V}$ below).

The flagellate hypothesis was easy to combine with Haeckel's Blastaea theory: one just had to replace Haeckel's amoeboid ancestor with a flagellate. This made the resulting theory more parsimonious, as it no longer required convergent evolution of flagella in protists and in animals. Perhaps because this synthesis appeared so intuitive, the concept of a flagellate ancestor has often been erroneously attributed to Haeckel himself in textbooks and in review papers of the $20^{\text {th }}$ and $21^{\text {st }}$ centuries, including by ourselves (Brunet and King 2017; Hyman 1940; Sogabe et al. 2019; Wainright et al. 1993; Willmer 1990).

\section{Box 2: Metchnikoff's flagellate hypothesis in his own words}

"The hypothesis which supposes that colonies of flagellate Infusoria were transformed into primitive Metazoa explains very clearly the most important phenomena of metazoan development. On this view, the segmentation of the egg, and especially the more primitive total segmentation, has been derived from the division which the Flagellata undergoes in building up a colony. In like manner the fact that the cells of so many blastospheres are ciliated is probably due to inheritance from the Flagellata. This hypothesis (...) enables us, as Bütschli first pointed out, to comprehend the origin of sexual multiplication. As a fact most embryologists, Ray Lankester and Balfour among others, have adopted this (...) hypothesis, and after a prolonged trial it has become a basis for further speculations. Having progressed this far, we should ask ourselves whether it is not possible, with the help of our present knowledge, to determine more or less exactly the nature of those Flagellate colonies from which the Metazoa are descended. Bütschli believes the Metazoa have had a double origin: the Sponges he derives from colonies of the Choano-Flagellata, the rest of the Metazoa from colonies of true Flagellata. Aside from the fact that there is very little ground for such a venturesome assumption, we must remember that the two groups (of Flagellata) are not sharply separated, and that the collar, which constitutes the main point of difference, is in some cases entirely retracted." ((Metchnikoff, 1886) translated in (Wilson, 1887))

\section{2}

84

\section{Saville-Kent's polyphyletic hypothesis of animal origins: sponges from flagellates and bilaterians from ciliates}

William Saville-Kent and Henry James-Clark - two of the first choanoflagellate experts - agreed with Metchnikoff on the evolution of sponges from choanoflagellate-like ancestors. But they disagreed (collegially) with Metchnikoff and (much more passionately) with Haeckel on the 
connection of sponges to animals (reviewed in (Leadbeater 2015)). This led Saville-Kent to conclude that animals had a dual origin: sponges had evolved from choanoflagellates, while all other animals had evolved from ciliates.

Haeckel initially thought of sponges as protists rather than animals (Haeckel 1876) but changed his mind after he discovered that they went through a gastrula stage (Haeckel 1872) - an observation that was doubted for more than a century but was confirmed in 2005 (Leys and Eerkes-Medrano 2005). Saville-Kent, on the other hand, strongly objected to the concept of sponges as animals, apparently because he thought that it conflicted with their connection to choanoflagellates. From the modern perspective, it seems clear that sponges can be related both to other animals (through exclusive common ancestry) and to the sister group of animals, the choanoflagellates (as was evident to Metchnikoff). However, both Haeckel and Saville-Kent seem to have strongly felt that sponges could either be related to one or the other, not both.

Saville-Kent's hostility toward Haeckel often got personal, and his comments on Haeckel's work contained a surprising density of personal attacks (e.g. (Kent 1878); reviewed in (Leadbeater 2015)). Saville-Kent thought the strongest blow to Haeckel's views was the discovery of his own "missing link" (see Footnote 1)- a living species that he felt was the perfect intermediate between choanoflagellates and sponges. Out of sheer spite ${ }^{4}$, Saville-Kent named that organism after his nemesis: Proterospongia haeckelii. P. haeckelii occupied a similar place in Saville-Kent's mind as Magosphaera did in Haeckel's: it was the keystone - and the concrete proof - of his theory. It was also similar in another way: no one else ever managed to observe it, and to this day, we still don't know if it was real (Figure 4).

P. haeckelii was a flat colony of choanoflagellates with a unique feature: just like a sponge, it had spatially differentiated cells. Collar cells positioned on the outside of the colony (similar to sponge choanocytes) coexisted with amoeboid cells on the inside (similar to sponge archeocytes). All cells were embedded in a shared flat layer of extracellular matrix. The classification of these two cell types within the same species of choanoflagellate was supported by observed interconversions between both. Saville-Kent's drawing of a mature colony with

\footnotetext{
${ }^{4}$ Naming species out of spite is a venerable tradition that dates back to Linnaeus, who named an especially smelly weed, Siegesbeckia, after one of his detractors. For a list, see https://www.science-shenanigans.com/species-namedout-of-spite/
} 


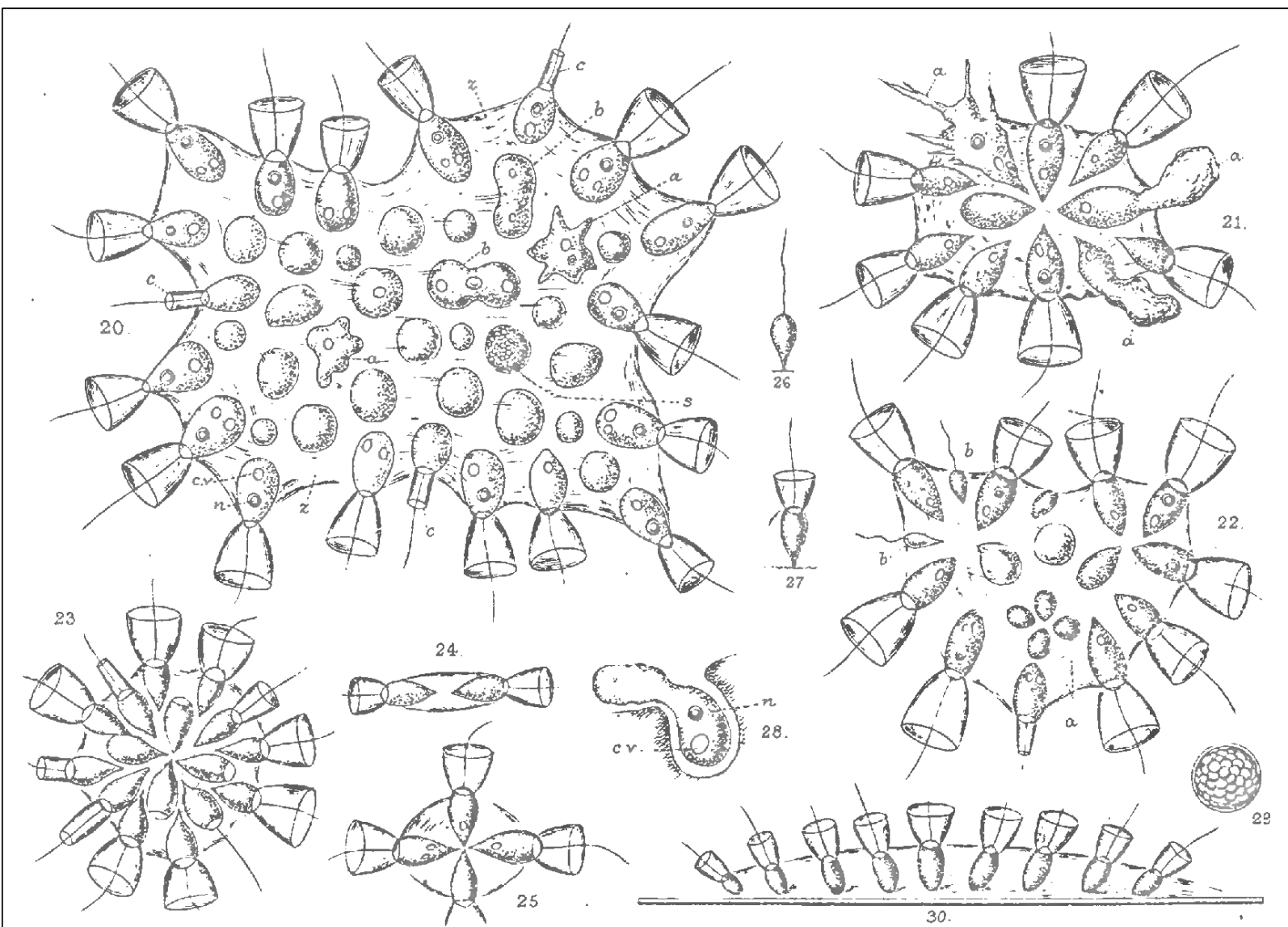

Figure 4. Mystery Organism 2: Proterospongia haeckelii (from (Kent 1882)). This purported colonial choanoflagellate was reported to contain both flagellated collar cells and amoeboid cells. All panels shown depict different developmental stages - arranged by Saville-Kent to minimize space on the page, and thus not in developmental order, which is as follows: $24,25,23,21,22$, and 20. 30 is a side-view of a mature colony (same stage as 20). 28 is a close-up of a cell in the process of becoming amoeboid. 26/27 and 29 are respectively the thecate and spore forms of $P$. haeckelii. reproduced since (Brusca and Brusca 2003; Buss 1987), but he also produced many lesserknown illustrations covering the complete developmental trajectory of $P$. haeckelii, including a single collar cell serially dividing into 2, 4, and 8 cells, after which amoeboid cells started differentiating (Fig. 4).

Saville-Kent was a thorough and careful microscopist, with his meticulous sketches anticipating structures that have been consistently detected and verified using modern techniques in microscopy. It is therefore unlikely that he would have simply misunderstood or misobserved an isolated specimen (such as a sponge larva). Instead, his description of the life history of $P$. haeckelii implies a detailed and extensive familiarity with multiple specimens, followed over an extended period of time. He was also a generally reliable observer, and his descriptions of other 
230 protists have been largely confirmed. Even though choanoflagellates have recently been shown

231 to switch to an amoeboid form under confinement (Brunet et al. 2020), it is unlikely that Saville-

232 Kent would have accidentally confined his samples: indeed, in the same book in which he

233 described P. haeckelii (Kent 1882), he reported the retraction of the choanoflagellate collar

234 complex under confinement and its regeneration after confinement release.

235

236

237

238

239

240

241

242

243

244

245

246

247

248

249

250

251

252

253

254

255

256

257

258

If an honest mistake is ruled out, then $P$. haeckelii might have been real - and close to Saville-Kent's description. However, efforts to re-isolate $P$. haeckelii from the source location in Kew Gardens by one of us (T.B., together with Barry Leadbeater) have failed so far ${ }^{5}$. Given the personal rivalry between Saville-Kent and Haeckel, an alternative interpretation is that the description of $P$. haeckelii by Saville-Kent was either partly or entirely fabricated, possibly to get back at Haeckel. As with Magosphaera, the existence of $P$. haeckelii remains a mystery.

As significant as Saville-Kent thought $P$. haeckelii was, he only considered it relevant to the origin of sponges, but not of other animals. Instead, he proposed that (most) animals had evolved from ciliates - not just once, but many times, with different ciliates giving rise to different animal lineages (Kent 1882). Saville-Kent was struck by the similarity in size, shape, and behavior between ciliates and small animals (both meiofaunal species - like rotifers or flatworms - and planktonic larvae; Fig. 5A). His idea initially drew skepticism (Lankester 1883) but had a few early supporters (Sedgwick 1895). It would, however, make a spectacular comeback and then recede again in the $20^{\text {th }}$ century.

\section{V. $20^{\text {th }}$ century: the rise and fall of the ciliate theory}

Saville-Kent was correct on one point: the similarities between ciliates and small animals of the interstitial fauna are striking (reviewed in (Leander 2008; Rundell and Leander 2010)). At first sight, one could easily mistake Paramecium for an acoel worm (Fig. 5B,C). Both are elongated, bilaterally symmetrical, nearly half a millimeter long, and densely covered in motile cilia. Acoel worms are minute animals of extreme simplicity (long believed to be flatworms, but now known to belong to a separate bilaterian lineage (Marlétaz 2019)). They lack excretory organs, an anus, and even a proper gut. Early histological studies emphasized that

\footnotetext{
${ }^{5}$ As a caveat, the reisolation of even a well-studied choanoflagellate species can be challenging. For example, the laboratory model species Salpingoeca rosetta (Dayel et al. 2011) has been isolated only once and we have been unable to re-isolate it from its source location despite repeated attempts.
} 
259 simplicity, and many observers went so far as to erroneously conclude that acoels lacked separate cells (except perhaps in the epidermis) and instead represented a single large syncytium containing floating nuclei. Uncertainty around this point persisted from the 1880 s to the $1960 \mathrm{~s}$, when electron microscopy finally demonstrated that acoels were actually fully cellular (see (Delage 1886; Pedersen 1964) for reviews).

In the meantime, however, the supposedly syncytial organization of acoels, together with their overall similarity to ciliates prompted a revival of Saville-Kent's ciliate theory of bilaterian origins. The idea was proposed independently by Jovan Hadži (1884-1972) and Otto Steinböck (1893-1969), and further elaborated by Earl D. Hanson (1927-1993) (Hadzi 1953, 1963; Hanson 1963, 1977; Steinböck 1963). These authors identified many purported homologies among ciliates and acoels: ciliary arrays of the former were homologized to the ciliated epidermis of the latter; the contractile infraciliary lattice of ciliates was inferred to represent an antecedent of acoel musculature; the digestive vacuoles were proposed to be equivalent to the acoel digestive mass; and pulsatile vacuoles in ciliates were considered homologous to nephridia (excretory organs that are absent in acoels but found in flatworms). The fact that ciliates only have two nuclei (a micronucleus and a macronucleus) and do not display a multicellular or even syncytial organization was countered by pointing to Opalina, a protist then considered to be a ciliate which possessed many nuclei underneath its cell membrane (and which is now known to be a heterokont that only convergently resembles ciliates (Cavalier-Smith and Chao 2006)). Like Saville-Kent, supporters of the ciliate theory explained the similarity between choanoflagellates and choanocytes by hypothesizing that sponges were specialized choanoflagellates, and thus unrelated to other animals. Animals were thus assumed to have had at least two independent origins in the protistan world, and maybe even three (with cnidarians possibly descending from amoebae (Hanson 1977)).

The hypothesis of the syncytial nature of acoels was finally disproven by electron microscopy in the mid-1960s (Pedersen 1964), but the ciliate theory of animal origins had by then taken a life of its own and survived the loss of its former central argument (Hanson 1977). As late as the 1980s-1990s, the ciliate hypothesis and the polyphyletic origin of animals were still often presented as the likeliest hypotheses of animal origins in popular texts and textbooks. In his best-seller Wonderful Life, Stephen Jay Gould wrote: "The vernacular term animal itself probably denotes a polyphyletic group, since sponges (almost surely), and probably corals and 


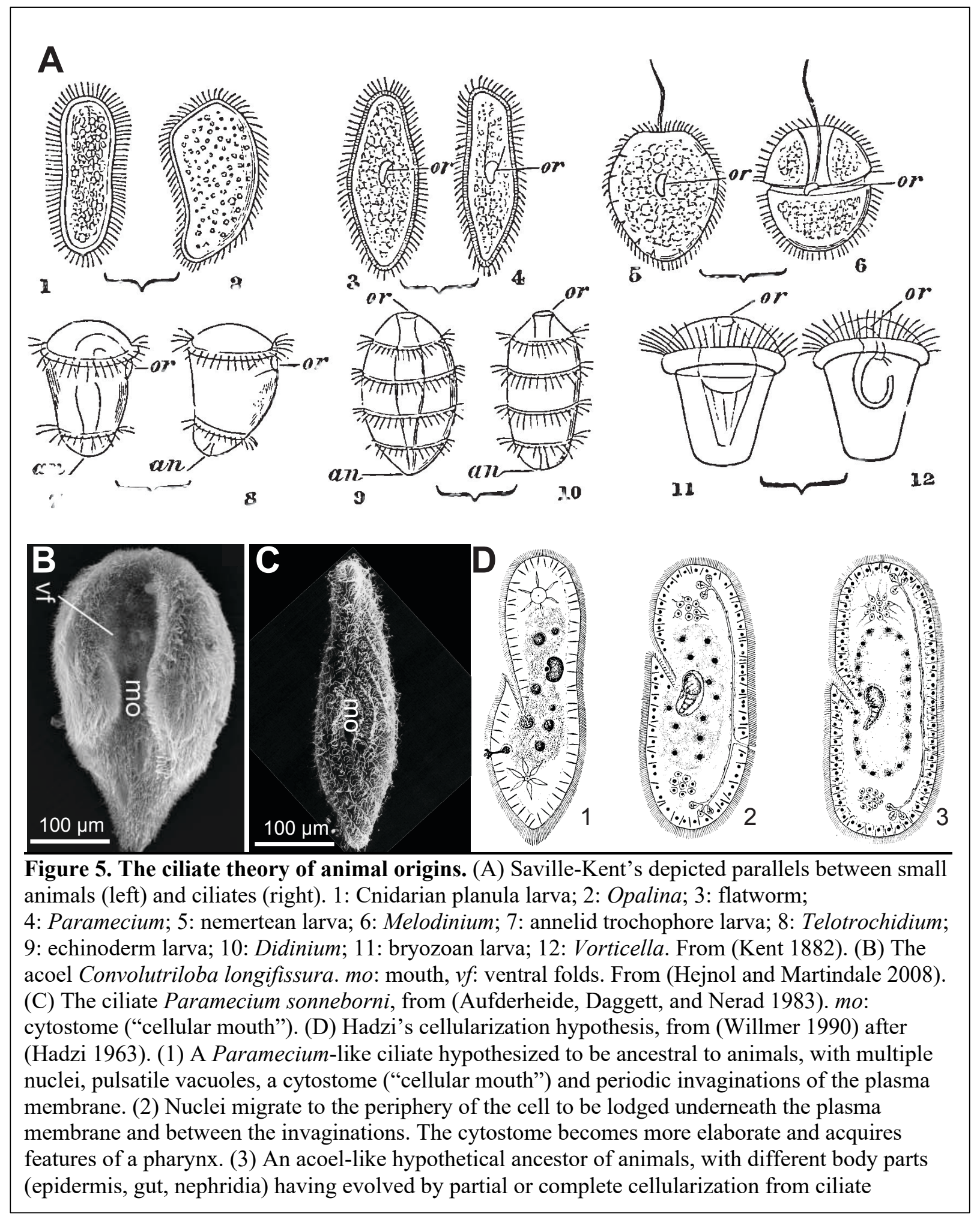
their allies as well, arose separately from unicellular ancestors - while all other animals of our 291 ordinary definition belong to a third distinct group." (Gould 1989). Similar statements could be

292 found in many contemporary zoology textbooks (Miller and Harley 1999; Mitchell, Mulmor, and 
293 Dolphin 1988; Willmer 1990), although a few were critical (Brusca and Brusca 1990).

294 Surprisingly, the ciliate theory survived the first molecular phylogenies as well: early studies

295

296

297

298

299

300

301

302

303

304

305

306

307

308

309

310

311

312

313

314

315

316

317

318

319

320

321

322

323

included only a few genes analyzed with simple, similarity-based algorithms and often failed to recover the monophyly of the animal kingdom, thus apparently lending credence to multiple independent origins of animals from several protist groups (Christen et al. 1991; Field et al. 1988; Lake 1990). It was only with larger datasets and better models of sequence evolution that a consistent picture of monophyletic animals closely related to choanoflagellates finally emerged, with ciliates relegated to a very distant branch (Wainright et al. 1993), making the ciliate theory untenable. Unsurprisingly, the hypothesized homologies also eventually failed to withstand molecular scrutiny. For example, the infraciliary contractile lattice of Paramecium was found to be made of centrins, a family of contractile proteins unrelated to actin and myosin, the contractile proteins of animal musculature (Levy et al. 1996).

With the benefit of hindsight, many of the arguments underlying the ciliate theory appear contrived. Yet, it convinced many - if not most - experts for nearly 30 years. We now know that its proponents were misled by an impressive suite of morphological convergences between metazoans, ciliates, and additional protists like Opalina. While the ciliate theory has now been dismissed as inconsistent with the modern eukaryotic phylogeny, it serves as a reminder of how much complexity - in morphology, patterning, and behavior - can be achieved by a single cell (Marshall 2020). The animal-like behaviors of ciliates, which fascinated scientists and philosophers at the turn of the $20^{\text {th }}$ century (Schloegel and Schmidgen 2002), are currently undergoing a renaissance as a research topic (Coyle et al. 2019; Dexter, Prabakaran, and Gunawardena 2019; Mathijssen et al. 2019; Wan and Jékely 2020), as are the mechanisms of their patterning and morphogenesis (Marshall 2020). Properly understood as an independent and unique evolutionary experiment in achieving levels of size and morphological complexity that rival those of small animals, ciliates remain as fascinating as ever.

\section{VI. $20^{\text {th }}$ century: the collared flagellate/Choanoblastaea model}

Although it had to compete with the ciliate theory for part of the $20^{\text {th }}$ century, Metchnikoff's concept of a choanoflagellate-like ancestor for all animals - and not just for sponges - was continuously supported by some authors (Hyman 1940; Nielsen and Norrevang 
1985; Rieger 1976; Salvini-Plawen 1978). These researchers were each convinced about the monophyly of animals based on shared features such as sperm and eggs, epithelia, and gastrulation. This implied that all animals had evolved from a single lineage of protist, of which choanoflagellates were considered the most plausible living representative as their similarity to choanocytes was so strong. This view received further support from the discovery of choanocytelike collar cells by electron microscopy in diverse animal phyla other than sponges (Brunet and King 2017; Lyons 1973; Nerrevang and Wingstrand 1970; Rieger 1976). Claus Nielsen named this revised Blastaea model - starting from a collared ancestor - the "Choanoblastaea" (Nielsen 2008) (Fig. 6).

While early molecular studies initially contradicted the Choanoblastaea hypothesis and suggested animal polyphyly (see section IV above), improved analyses with more data and better statistical models of sequence evolution ended up consistently supporting the monophyly of animals and their sister-group relationship to choanoflagellates (King et al. 2008; King, Hittinger, and Carroll 2003; King and Carroll 2001; Lang et al. 2002; Rokas et al. 2003; RuizTrillo et al. 2008; Wainright et al. 1993). Unlike hypothesized homologies between ciliates and animals, the inferred homology of the collar complex in animals and choanoflagellates survived molecular and biochemical analyses, which confirmed that the collar is composed of homologous cytoskeletal filaments in both choanoflagellates, sponges, and other animals (reviewed in (Brunet and King 2017; Leadbeater 2015)). The hypothesis of the homology of the collar complex - proposed on morphological grounds in the $19^{\text {th }}$ century - thus appears to have been predictive (Colgren and Nichols 2020) and is now accepted by most authors (but see (Mah, Christensen-Dalsgaard, and Leys 2014; Sogabe et al. 2019) for exceptions and (Brunet and King 2017; Colgren and Nichols 2020; Myers 2019) for responses).

Despite its support from the data, the Choanoblastaea model leaves some questions unresolved. One is the similarity of crawling amoeboid cells, widespread in animals, to the amoeboid motility of diverse protists. While some authors explicitly ascribed that similarity to evolutionary convergence (Cavalier-Smith 2017), few directly recognized or addressed the issue. While one solution could have been to revive Haeckel's amoeboid hypothesis, a strict interpretation of his hypothesis had clearly become incompatible with structural information that had emerged in the $20^{\text {th }}$ century showing the homology of flagella in animals and diverse protists (reviewed in (Margulis 1981)). Instead, one parsimonious way to account for all the data has 

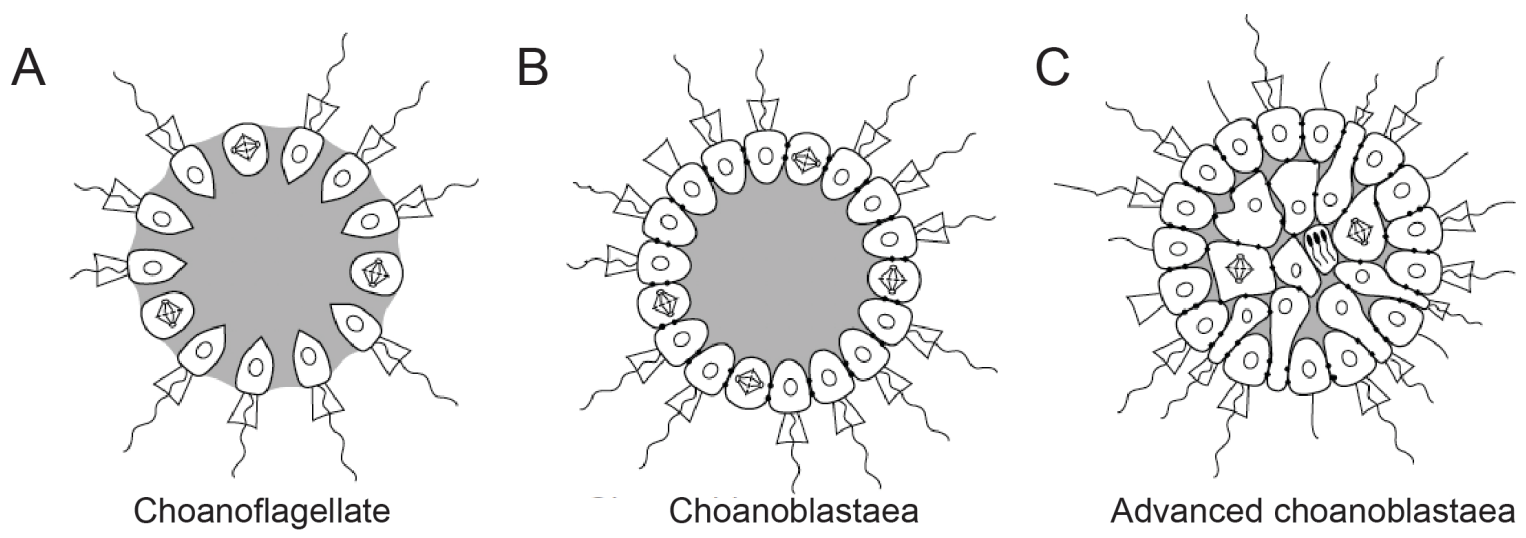

Figure 6. The Choanoblastaea model of animal origins (Nielsen 2008). (A) A modern choanoflagellate rosette colony, proposed to resemble early stem-animals. Cells are arranged as a sphere surrounding a shared core of extracellular matrix (dark grey). (B) A hypothetical later stemanimal ("Choanoblastaea"), in which cells have become adjacent and have evolved intercellular junctions and now form a sealed epithelial sphere. (C) A later hypothetical stem-animal ("Advanced choanoblastaea") in which some cells have become amoeboid and populated the inner space of the colony (compare P. haeckelii, Fig. 4). Note that cell division is now restricted to those inner cells.

been to reconstruct the progenitor of animals as a shape-shifter: sometimes flagellate, sometimes amoeba, and maybe more.

\section{VII. $20^{\text {th }}$ century: the amoeboflagellate model and the synzoospore model}

Complex life cycles in protists have been known since the $19^{\text {th }}$ century. In 1898 , the British medical doctor Ronald Ross (1857-1932) described the different life stages of the unicellular parasite that causes malaria, Plasmodium falciparum (reviewed in (Cox 2002)).A year later, the Austrian biologist Franz Schardinger (1853-1920) discovered Naegleria gruberi (then named Amoeba gruberi), a free-living amoeba that had the unusual ability to transdifferentiate into a flagellate form (Schardinger 1899).

The transition between the amoeboid and the flagellate forms of Naegleria is reminiscent of the reversible transdifferentiation between the flagellated choanocytes and the amoeboid archeocytes of sponges (Fig. 7) that was already known to Saville-Kent (Kent 1882) and later confirmed by modern studies (Nakanishi, Sogabe, and Degnan 2014; Sogabe et al. 2019)).

In spite of this parallel, shape-shifting protists such as Naegleria were apparently never considered relevant to animal origins before the mid- $20^{\text {th }}$ century, when the Soviet biologist 
A

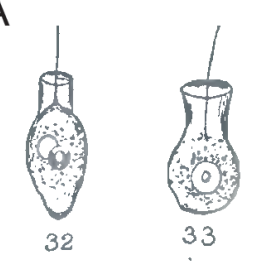

$\mathrm{B}$
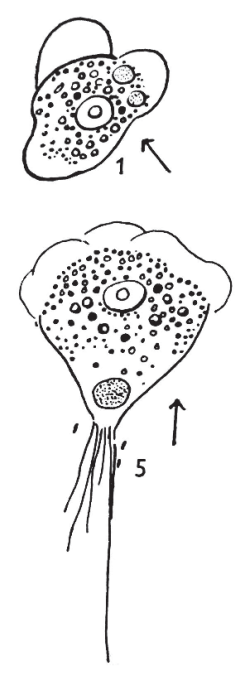
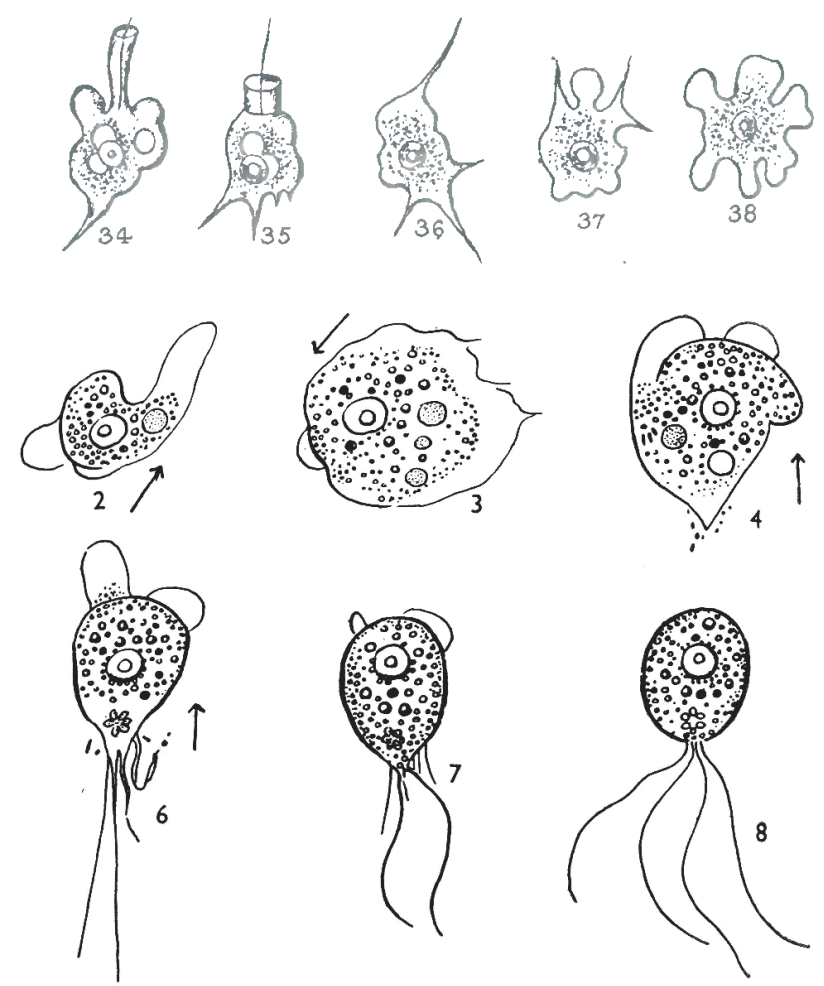

Figure 7. Interconversions between flagellate and amoeboid phenotypes in sponge cell transdifferentiation. (A) (Kent 1882) and in Naegleria development (B) (Willmer 1971).

Alexey Zakhvatkin (1906-1950, alternatively spelled Sachwatkin) and the British biologist E. N. Willmer (1902-2001) independently hypothesized that the elaborate life cycles of animals might have their roots in the unicellular world. In his treatise Comparative embryology of the low invertebrates ((Zakhvatkin 1949) for the Russian original and (Sachwatkin 1956) for the German translation, which we consulted), Zakhvatkin explicitly compared the complex life cycles of protists and animals. By comparing animal cell differentiation with the reversible amoeboid/flagellate switches of Naegleria gruberi ${ }^{6}$ and of Polytomella citri (a parasitic green $\operatorname{alga}^{7}$ (Kater 1925)), Zakhvatkin suggested animals evolved from an amoeboflagellate. He also noted that the serial, dichotomous cleavage at constant volume of animal zygotes (a process called "palintomy") had parallels in several protists, including dinoflagellates and green algae, in which it resulted in a mass of flagellated spores (or "zoospores") that eventually dissociated and

\footnotetext{
${ }^{6}$ Which he referred to as Vahlkampfia gruberi.

${ }^{7}$ P. citri is a secondarily non-photosynthetic, parasitic green alga, and thus belongs to a lineage whose sequenced representatives have lost regulators of cell crawling such as SCAR/WAVE (Fritz-Laylin, Lord, and Mullins 2017) and myosin II (Sebé-Pedrós et al. 2014). While the genome of $P$. citri itself has not been sequenced, it is interesting to wonder how amoeboid mobility could function in this species if it also lacks those genes.
} 
384

385

386

387

388

389

390

391

392

393

394

395

396

397

398

399

400

401

402

403

404

405

406

407

408

409

410

411

412

413

underwent dispersal. Zakhvatkin suggested that the morula stage of animal development might have evolved from zoospores that failed to separate - a "synzoospore."

Because Zakhvatkin's work was only available in Russian and in German, it did not immediately reach the English-speaking world. It is thus independently of Zakhvatkin, and based on his own studies of Naegleria, that Willmer came to remarkably similar conclusions and proposed an amoeboflagellate ancestry for animals in his 1971 book Cytology and Evolution (Willmer 1971). While he did not believe that Naegleria was directly related to animals, he thought it gave an idea of what animal ancestors might have looked like.

Zakhvatkin's and Willmer's ideas seem to have gone mostly unnoticed in their time, and debates regarding animal origins remained dominated by the ciliate theory and the flagellate theory. It is only in the last decade - the 2010 s - that the concept of a protist ancestor with a complex life history has undergone a revival.

\section{VIII. $21^{\text {st }}$ century: how complex was the metazoan precursor?}

In 2009, Zahkvatkin's idea were shared with a broader audience thanks to a review paper which presented his theory in English and named it the "temporal-to-spatial transition" model of animal origins (Mikhailov et al. 2009). Nearly at the same time, molecular phylogenies revealed that the previously enigmatic filasterans and ichthyosporeans (Ruiz-Trillo et al. 2008) are the closest known living relatives of choanozoans (the clade formed by choanoflagellates and animals; Fig. 2). Together, choanozoans, ichthyosporeans and filasterans form the clade Holozoa $^{8}$. Interestingly, single-celled holozoans assume diverse cellular forms (including flagellates, amoebae, and cystic forms), and many of them have complex life histories with multiple phenotypes (as do choanoflagellates, which have sessile, swimming and colonial flagellate forms, and often spores as well (Leadbeater 2015)).

Several studies have investigated the cellular and molecular basis for the complex life histories of unicellular holozoans (Dayel et al. 2011; Fairclough, Dayel, and King 2010; SebéPedrós et al. 2013; Suga and Ruiz-Trillo 2013). Remarkably, many of these cell type transitions correlate with chromatin remodelling and pre- and post-transcriptional regulation (Dudin et al. 2019; Fairclough et al. 2013; Sebé-Pedrós, Ballaré, et al. 2016; Sebé-Pedrós, Peña, et al. 2016),

\footnotetext{
${ }^{8} \mathrm{~A}$ few additional lineages (such as corallochytrids) have since been added.
} 

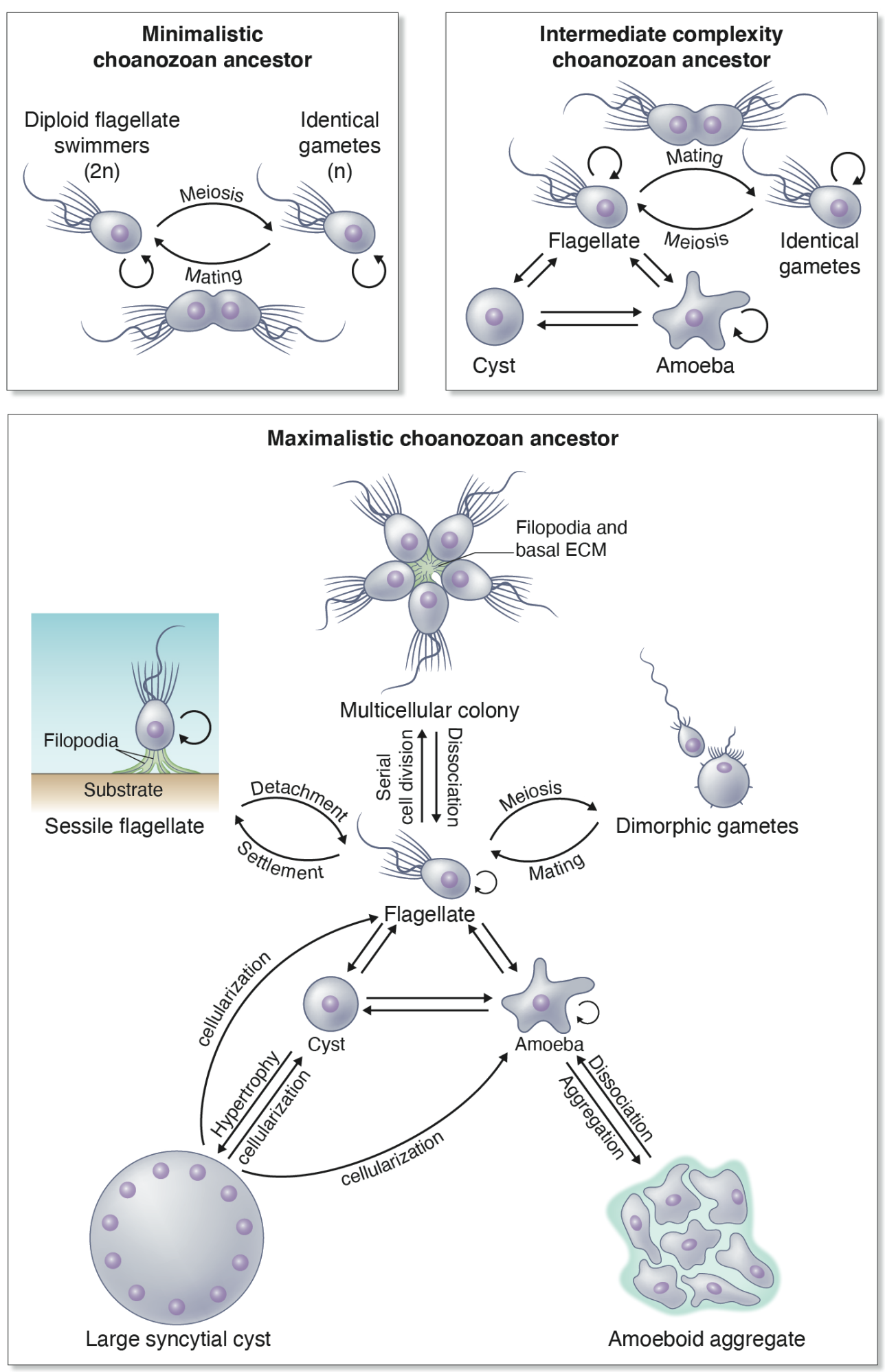

Figure 8. Current minimalistic, intermediate and maximalistic concepts of the last common ancestor of animals and choanoflagellates. The minimalistic ancestor (upper left) is reconstructed as a collared flagellate with a sexual cycle, but no multicellularity and no other cell phenotype. The intermediate ancestor (upper right) is also assumed to have been obligately unicellular, but can transdifferentiate into several forms, including a collared flagellate, an amoeba (similar to animal crawling cells such as macrophages), and a quiescent cyst (perhaps similar to animal quiescent stem 
(Figure 8, continued.) cells or egg cells). The maximalistic ancestor (bottom) displays several forms of facultative multicellularity and combines several additional phenotypes known in single-celled relatives of animals, all of which have parallels among animal cell types and represent hypothetical evolutionary precursors of the latter. Spherical multicellular colonies of flagellates, similar to those of some choanoflagellates (Dayel et al. 2011), resemble the Morula stage of animal embryos. Sessile flagellated cells adhere to the substrate by a combination of filopodia and secreted extracellular matrix (ECM, green), as in modern choanoflagellates (Dayel et al. 2011) and in the filasteran Capsaspora (Parra-Acero et al. 2018, 2020). This might have prefigured the adhesion of animal epithelial cells to the basal lamina. Amoeboid cells are proposed to undergo aggregative multicellularity, similar to Capsaspora (Sebé-Pedrós et al. 2013) and to dissociated sponge cells (Dunham et al. 1983). Finally, cysts are proposed to undergo hypertrophy by nuclear proliferation without cytokinesis, resulting in a syncytium that can cellularize at constant volume to revert to a uninucleated state, as in modern ichthyosporeans (Dudin et al. 2019; Suga and Ruiz-Trillo 2013) and chytrid fungi (Medina et al. 2020). This process bears some similarity to the palintomic cleavage of animal zygotes. (Drawing: Debbie Maizels)

415

416

417

418

419

420

421

422

423

424

425

426

427

428

429

430

431

432

433

434

suggesting the existence of shared mechanisms with animal cell differentiation. Adding to this picture of generally dynamic cell phenotypes, novel amoeboflagellate species were recently discovered among holozoans (Hehenberger et al. 2017; Tikhonenkov, Hehenberger, et al. 2020). Finally, choanoflagellates themselves turned out to be able to reversibly switch to an amoeboid phenotype in response to spatial confinement (Brunet et al. 2020), thus reviving Saville-Kent's concept of amoeboid phenotypes in choanoflagellates. Overall, these data converged to suggest that our ancestors along the holozoan stem-line - including the choanozoan ancestor - almost certainly had the ability to generate more cell phenotypes than just a collared flagellate, potentially paving the way to animal cell differentiation; and modern variants of the Choanoblastaea hypothesis have started to incorporate that idea (Arendt et al. 2015).

What did the choanozoan ancestor look like? Although we have made progress since Haeckel, Metchnikoff and Saville-Kent, many questions remain open. In Figure 8, we have illustrated two extreme options - a "minimalistic ancestor" (a simple collared flagellate without other phenotypes) and a "maximalistic ancestor" that combines several cell phenotypes frequently found in in single-celled holozoans (most of which have an equivalent in animal biology) - along with an intermediate scenario that captures features we consider likely to have existed in the protistan ancestor of animals. The life cycle of this long extinct organism might have included "facultative features" such as amoeboid migration, encystment, clonal multicellularity (with or without palintomy) and aggregative multicellularity. 
Interestingly, comparative genomics has revealed that many genes thought to be animalspecific are present in their single-celled relatives - but often with a patchy and mosaic distribution, indicating rampant gene loss in most lineages (Richter et al. 2018; Suga et al. 2013). This suggests that the last choanozoan common ancestor possessed a mosaic of features that is not fully realized in any of its living relatives or descendants. We think this lends credibility to the possibility of a "maximalistic ancestor." Future work will help to refine the "checklist" of ancestral choanozoan features - which will not necessarily include all those we depicted in Figure 8, nor will necessarily be restricted to them.

\section{Conclusion}

The past has only left incomplete traces, and our understanding of it is inevitably simplified. There is, however, another force that often pushes us to simplification: the urge to summarize history as a linear narrative that leads to the present. In this review, we have strived to embrace the complexity of the past - both of our scientific predecessors, and of our evolutionary ancestors. We hope the winding history of our field is worth appreciating for itself and for the many small gems it contains, before trying to extract an - inevitably simplified global message.

Nonetheless, a few general themes emerge. The diversity of historical hypotheses simultaneously reflects the complexity of the problem itself, the limited information available at the time, and the personal assumptions and preferences of their authors. On the one hand, morphological data were clearly confounded by multiple events of evolutionary convergence (such as between ciliates and animals), parallelism, and rampant loss. Solving the problem from morphology only was genuinely challenging (even after the advent of electron microscopy), and involved some degree of subjective judgment. On the other hand, many authors seemed to have made the task unnecessarily more difficult by assuming that the last single-celled ancestors of animals necessarily had an exact equivalent within living protists - while this ancestor likely had its own, unique combination of features that is not necessarily represented today. This point has become increasingly salient in the past few years, and we expect it to remain central to future research. Consistently, several species of single-celled holozoans with novel phenotypes have 
466

467

468

469

470

471

472

473

474

475

476

477

478

479

480

481

482

483

484

485

486

487

488

489

490

491

492

493

494

495

496

497

498

499

been newly described in the past few years (Brunet et al. 2019; Hehenberger et al. 2017;

Tikhonenkov, Hehenberger, et al. 2020; Tikhonenkov, Mikhailov, et al. 2020), and metagenomic surveys have provided evidence for the existence of additional undiscovered holozoan lineages (Arroyo et al. 2020; Del Campo and Ruiz-Trillo 2013). Further exploration of single-celled biodiversity thus holds the promise to enrich our reconstitution of animal ancestors - and eventually maybe even to clarify the mysteries of Magosphaera planula and Proterospongia haeckelii.

Another point of interest is the way in which past controversies were resolved. Many debates could only be settled after the invention of new techniques; yet, technical innovations alone were rarely sufficient. The first molecular phylogenies, for example, were rather inaccurate. Consensus was only reached after commonly accepted standards of evidence were agreed upon, and once multiple independent, technically solid studies converged toward the same answer. At a time where a new wealth of molecular data (notably from single-cell techniques) is promising to bring an unprecedented quantity of evidence to bear on the study the evolution of cell phenotypes, we hope that our historical summary can be read both as a cautionary tale, and as a reason for optimism.

\section{Acknowledgements}

We thank Debbie Maizels for help with the figures, Elliott Smith of the UC Berkeley library for access to scans of Haeckel books, Iñaki Ruiz-Trillo for feedback on Figure 8, Omaya Dudin for discussions on ichthyosporeans and palintomy, and the entire King lab for stimulating discussions.

\section{References}

We are especially indebted to the following historical reviews: (Leadbeater 2015; Leadbeater and McCready 2002; Nielsen 2008, 2012; Salvini-Plawen 1978; Willmer 1990)

Arendt, Detlev, Elia Benito-Gutierrez, Thibaut Brunet, and Heather Marlow. 2015. "Gastric Pouches and the Mucociliary Sole: Setting the Stage for Nervous System Evolution." Philosophical Transactions of the Royal Society B: Biological Sciences 370(1684):20150286.

Arroyo, Alicia S., Romain Iannes, Eric Bapteste, and Iñaki Ruiz-Trillo. 2020. "Gene Similarity Networks Unveil a Potential Novel Unicellular Group Closely Related to Animals from the Tara Oceans Expedition." Genome 

Biology and Evolution 12(9):1664-1678.

Aufderheide, Karl J., Pierre-Marc M. Daggett, and Thomas A. Nerad. 1983. "Paramecium Sonneborni n. Sp., a New Member of the Paramecium Aurelia Species-Complex.” The Journal of Protozoology 30(1):128-31.

Brunet, Thibaut, Marvin Albert, William Roman, Danielle Spitzer, and Nicole King. 2020 . "A Flagellate-toAmoeboid Switch in the Closest Living Relatives of Animals." BioRxiv.

Brunet, Thibaut and Nicole King. 2017. "The Origin of Animal Multicellularity and Cell Differentiation." Developmental Cell 43(2):124-40.

Brunet, Thibaut, Ben T. Larson, Tess A. Linden, Mark J. A. Vermeij, Kent McDonald, and Nicole King. 2019. "Light-Regulated Collective Contractility in a Multicellular Choanoflagellate." Science 366(6463):326-34.

Brusca, Richard C. and Gary J. Brusca. 1990. Invertebrates. 1st ed. Sunderland, Mass.: Sinauer Associates.

Brusca, Richard C. and Gary J. Brusca. 2003. Invertebrates. 2nd ed. Sinauer Associates, Inc.

Buss, Leo W. 1987. The Evolution of Individuality. Princeton University Press.

Bütschli, Otto. 1884. "Bemerkungen Zur Gastraea-Theorie.” Morph. Jahrb. 9:415-27.

Del Campo, Javier and Iñaki Ruiz-Trillo. 2013. "Environmental Survey Meta-Analysis Reveals Hidden Diversity among Unicellular Opisthokonts." Molecular Biology and Evolution 30(4):802-5.

Cavalier-Smith, Thomas. 2017. "Origin of Animal Multicellularity: Precursors, Causes, Consequences - the Choanoflagellate/Sponge Transition, Neurogenesis and the Cambrian Explosion." Philosophical Transactions of the Royal Society B: Biological Sciences 372(1713):20150476.

Cavalier-Smith, Thomas and Ema E. Y. Chao. 2006. "Phylogeny and Megasystematics of Phagotrophic Heterokonts (Kingdom Chromista)." Journal of Molecular Evolution 62(4):388-420.

Christen, R., A. Ratto, A. Baroin, R. Perasso, K. G. Grell, and A. Adoutte. 1991. "An Analysis of the Origin of Metazoans, Using Comparisons of Partial Sequences of the 28S RNA, Reveals an Early Emergence of Triploblasts.” EMBO Journal 10(3):499-503.

Colgren, Jeffrey and Scott A. Nichols. 2020. "The Significance of Sponges for Comparative Studies of Developmental Evolution.” Wiley Interdisciplinary Reviews: Developmental Biology 9(2):e359.

Cox, F. E. G. 2002. "History of Human Parasitology." Clinical Microbiology Reviews 15(4):595-612.

Coyle, Scott M., Eliott M. Flaum, Hongquan Li, Deepak Krishnamurthy, and Manu Prakash. 2019. "Coupled Active Systems Encode an Emergent Hunting Behavior in the Unicellular Predator Lacrymaria Olor." Current Biology 29(22):3838-50.

Darwin, Charles. 1859. The Origin of Species by Means of Natural Selection; or the Preservation of Favoured Races in the Struggle for Life. Murray.

Darwin, Charles and Alfred Wallace. 1858. "On the Tendency of Species to Form Varieties; and on the Perpetuation of Varieties and Species by Natural Means of Selection." Journal of the Proceedings of the Linnean Society of London. Zoology 3(9):46-62.

Dayel, Mark J., Rosanna A. Alegado, Stephen R. Fairclough, Tera C. Levin, Scott A. Nichols, Kent McDonald, and Nicole King. 2011. "Cell Differentiation and Morphogenesis in the Colony-Forming Choanoflagellate Salpingoeca Rosetta.” Developmental Biology 357(1):73-82.

Delage, Yves. 1886. "Etudes Histologiques Sur Les Planaires Rhabdocoeles Acoeles.” Archives de Zoologie Expérimentale et Générale II(4):109-60.

Dexter, Joseph P., Sudhakaran Prabakaran, and Jeremy Gunawardena. 2019. "A Complex Hierarchy of Avoidance Behaviors in a Single-Cell Eukaryote." Current Biology 29(24):4323-29.

Dudin, Omaya, Andrej Ondracka, Xavier Grau-Bové, Arthur A. B. Haraldsen, Atsushi Toyoda, Hiroshi Suga, Jon Bråte, and Iñaki Ruiz-Trillo. 2019. "A Unicellular Relative of Animals Generates a Layer of Polarized Cells by Actomyosin-Dependent Cellularization.” ELife 2019(8):e49801. 
Dunham, P., C. Anderson, A. B. Rich, and G. Weissmann. 1983. "Stimulus-Response Coupling in Sponge Cell Aggregation: Evidence for Calcium as an Intracellular Messenger." Proceedings of the National Academy of Sciences of the United States of America 80(15):4756-60.

Ereskovsky, Alexander V. 2010. The Comparative Embryology of Sponges. Springer.

Fairclough, Stephen R., Zehua Chen, Eric Kramer, Qiandong Zeng, Sarah Young, Hugh M. Robertson, Emina Begovic, Daniel J. Richter, Carsten Russ, M. Jody Westbrook, Gerard Manning, B. Franz Lang, Brian Haas, Chad Nusbaum, and Nicole King. 2013. "Premetazoan Genome Evolution and the Regulation of Cell Differentiation in the Choanoflagellate Salpingoeca Rosetta." Genome Biology 14(2):1-15.

Fairclough, Stephen R., Mark J. Dayel, and Nicole King. 2010. "Multicellular Development in a Choanoflagellate." Current Biology 20(20):R875-76.

Field, Katharine G., Gary J. Olsen, David J. Lane, Stephen J. Giovannoni, Michael T. Ghiselin, Elizabeth C. Raff, Norman R. Pace, and Rudolf A. Raff. 1988. "Molecular Phylogeny of the Animal Kingdom." Science 239(4841):748-53.

Franz, Victor. 1924. Geschichte Der Organismen. Fischer.

Franzen, Wilfried. 1988. "Oogenesis and Larval Development of Scypha Ciliata (Porifera, Calcarea)." Zoomorphology 107(6):349-357.

Fritz-Laylin, Lillian K., Samuel J. Lord, and R. Dyche Mullins. 2017. "WASP and SCAR Are Evolutionarily Conserved in Actin-Filled Pseudopod-Based Motility." Journal of Cell Biology 216(6):1673-1688.

Gould, Stephen Jay. 1977. Ontogeny and Phylogeny. Belknap Press.

Gould, Stephen Jay. 1989. Wonderful Life: The Burgess Shale and the Nature of History. New York: W. W. Norton \& Co.

Grau-Bové, Xavier, Guifré Torruella, Stuart Donachie, Hiroshi Suga, Guy Leonard, Thomas A. Richards, and Iñaki Ruiz-Trillo. 2017. "Dynamics of Genomic Innovation in the Unicellular Ancestry of Animals." ELife.

Hadzi, J. 1953. "An Attempt to Reconstruct the System of Animal Classification.” Systematic Zoology 2(4):145-54.

Hadzi, J. 1963. The Evolution of the Metazoa. Pergamon Press.

Haeckel, Ernst. 1870. Biologische Studien. Erstes Heft: Studien Über Moneren Und Andere Protisten. Leipzig, Engelmann.

Haeckel, Ernst. 1872. Die Kalkschwämme. Eine Monographie. Berlin: G. Reimer.

Haeckel, Ernst. 1874. The Evolution of Man: A Popular Exposition of the Principal Points of Human Ontogeny and Phylogeny.

Haeckel, Ernst. 1876. The History of Creation, or the Development of the Earth and Its Inhabitants by the Action of Natural Causes, Volume 2. 1 st ed. London: Henry S. King \& Co.

Haeckel, Ernst. 1914. The History of Creation, or the Development of the Earth and Its Inhabitants by the Action of Natural Causes, Volume 2. 6th ed. New York: D. Appleton \& Co.

Hanson, Earl D. 1963. "Homologies and the Ciliate Origin of the Eumetazoa." in The Lower Metazoa, edited by E. C. Dougherty, Z. N. Brown, E. D. Hanson, and W. D. Hartman. Cambridge University Press.

Hanson, Earl D. 1977. The Origin and Early Evolution of Animals. London: Pitman.

Hardy, A. C. 1953. "On the Origin of the Metazoa.” Journal of Microscopical Science 94(4):441-43.

Hassett, Brandon T., J. Andrés López, and Rolf Gradinger. 2015. “Two New Species of Marine Saprotrophic Sphaeroformids in the Mesomycetozoea Isolated From the Sub-Arctic Bering Sea." Protist.

Hehenberger, Elisabeth, Denis V. Tikhonenkov, Martin Kolisko, Javier del Campo, Anton S. Esaulov, Alexander P. Mylnikov, and Patrick J. Keeling. 2017. "Novel Predators Reshape Holozoan Phylogeny and Reveal the Presence of a Two-Component Signaling System in the Ancestor of Animals." Current Biology 27(13):204350. 
588

589

590

591

592

593

594

595

596

597

598

599

600

601

602

603

604

605

606

607

608

609

610

611

612

613

614

615

616

617

618

619

620

621

622

623

624

625

626

627

628

629

630

631

632

633
Hejnol, Andreas and Mark Q. Martindale. 2008. “Acoel Development Indicates the Independent Evolution of the Bilaterian Mouth and Anus.” Nature 456(7220):382-86.

Hyman, Libbie Henrietta. 1940. The Invertebrates: Protozoa through Ctenophora. McGraw-Hill Book Company.

James-Clark, Henry. 1867. "On the Spongiae Ciliatae as Infusoria Flagellata: Or Observations on the Structure, Animality and Relationship of Leucosolenia Botryoides Bowerbank." Memoirs of the Boston Society of Natural History 1:305-40.

Kater, J. McA. 1925. "Morphology and Life History of Polytomella Citri Sp. Nov." The Biological Bulletin 49(3):213-36.

Kent, William Saville. 1878. “Observations upon Prof. Ernst Haeckel's 'Physemaria' and on the Affinity of the Sponges." Annals and Magazine of Natural History 5(1):1-17.

Kent, William Saville. 1882. A Manual of the Infusoria. D. Bogue.

King, N. and S. B. Carroll. 2001. "A Receptor Tyrosine Kinase from Choanoflagellates: Molecular Insights into Early Animal Evolution." Proceedings of the National Academy of Sciences of the United States of America 98(26):15032-37.

King, Nicole. 2004. “The Unicellular Ancestry of Animal Development.” Developmental Cell 7(3):313-25.

King, Nicole, Christopher T. Hittinger, and Sean B. Carroll. 2003. "Evolution of Key Cell Signaling and Adhesion Protein Families Predates Animal Origins.” Science 301(5631):361-63.

King, Nicole, M. Jody Westbrook, Susan L. Young, Alan Kuo, Monika Abedin, Jarrod Chapman, Stephen Fairclough, Uffe Hellsten, Yoh Isogai, Ivica Letunic, Michael Marr, David Pincus, Nicholas Putnam, Antonis Rokas, Kevin J. Wright, Richard Zuzow, William Dirks, Matthew Good, David Goodstein, Derek Lemons, Wanqing Li, Jessica B. Lyons, Andrea Morris, Scott Nichols, Daniel J. Richter, Asaf Salamov, Peer Bork, Wendell A. Lim, Gerard Manning, W. Todd Miller, William McGinnis, Harris Shapiro, Robert Tjian, Igor V. Grigoriev, and Daniel Rokhsar. 2008. "The Genome of the Choanoflagellate Monosiga Brevicollis and the Origin of Metazoans.” Nature 451(7180):783-88.

Lake, J. A. 1990. “Origin of the Metazoa.” Proceedings of the National Academy of Sciences of the United States of America 87(2):763-66.

Lamarck, Jean-Baptiste. 1809. Philosophie Zoologique, Ou Exposition Des Considérations Relatives à l'histoire Naturelle Des Animaux. Musée d'Histoire Naturelle.

Lang, B. F., C. O’Kelly, T. Nerad, M. W. Gray, and G. Burger. 2002. “The Closest Unicellular Relatives of Animals." Current Biology 12(20):1773-78.

Lankester, E. Ray. 1883. "A Manual of the Infusoria; Including a Description of All Known Flagellate, Ciliate, and Tentaculiferous Protozoa (Book Review)." Nature 27:601-3.

Leadbeater, Barry S. C. 2015. The Choanoflagellates. Cambridge University Press.

Leadbeater, Barry S. C. and Sharon M. M. McCready. 2002. “The Flagellates: Historical Perspectives.” P. 414 in The Flagellates. Unity, Diversity, and Evolution, edited by B. S. C. Leadbeater and J. C. Green. Taylor \& Francis.

Leander, Brian S. 2008. "A Hierarchical View of Convergent Evolution in Microbial Eukaryotes.” Journal of Eukaryotic Microbiology 55(2):59-68.

van Leeuwenhoek, Antony. 1677. “Observations, Communicated to the Publisher by Mr. Antony van Leewenhoeck, in a Dutch Letter of the 9th Octob. 1676. Here English'd: Concerning Little Animals by Him Observed in Rain-Well-Sea- and Snow Water; as Also in Water Wherein Pepper Had Lain Infus." Philosophical Transactions of the Royal Society of London 12(133):821-31.

Levit, Georgy S., Uwe Hoßfeld, Benjamin Naumann, Paul Lukas, and Lennart Olsson. 2020. “The Biogenetic Law and the Gastraea Theory: From Ernst Haeckel's Discoveries to Contemporary Views." Preprints.

Levy, Yaron Y., Elaine Y. Lai, Stephen P. Remillard, Matthew B. Heintzelman, and Chandler Fulton. 1996. "Centrin Is a Conserved Protein That Forms Diverse Associations with Centrioles and MTOCs in Naegleria 
634

635

636

637

638

639

640

641

642

643

644

645

646

647

648

649

650

651

652

653

654

655

656

657

658

659

660

661

662

663

664

665

666

667

668

669

670

671

672

673

674

675

676

677

and Other Organisms.” Cell Motility and the Cytoskeleton 33(4):298-323.

Leys, Sally P. and Dafne Eerkes-Medrano. 2005. “Gastrulation in Calcareous Sponges: In Search of Haeckel's Gastraea." Integrative and Comparative Biology 45(2):342-51.

Leys, Sally P. and April Hill. 2012. "The Physiology and Molecular Biology of Sponge Tissues." in Advances in Marine Biology.

Lyons, Kathleen M. 1973. "Collar Cells in Planula and Adult Tentacle Ectoderm of the Solitary Coral Balanophyllia Regia (Anthozoa Eupsammiidae).” Zeitschrift Für Zellforschung Und Mikroskopische Anatomie 145(1):5774.

Mah, Jasmine L., Karen K. Christensen-Dalsgaard, and Sally P. Leys. 2014. "Choanoflagellate and Choanocyte Collar-Flagellar Systems and the Assumption of Homology." Evolution and Development 16(1):25-37.

Margulis, Lynn. 1981. Symbiosis in Cell Evolution. W.H.Freeman \& Co Ltd.

Marlétaz, Ferdinand. 2019. “Zoology: Worming into the Origin of Bilaterians.” Current Biology 29(12):R577-79.

Marshall, Wallace F. 2020. "Pattern Formation and Complexity in Single Cells.” Current Biology 30(10):R544-52.

Mathijssen, Arnold J. T. M., Joshua Culver, M. Saad Bhamla, and Manu Prakash. 2019. "Collective Intercellular Communication through Ultra-Fast Hydrodynamic Trigger Waves.” Nature 571(7766):560-64.

Medina, Edgar M., Kristyn A. Robinson, Kimberly Bellingham-Johnstun, Giuseppe Ianiri, Caroline Laplante, Lillian K. Fritz-Laylin, and Nicolas E. Buchler. 2020. "Genetic Transformation of Spizellomyces Punctatus, a Resource for Studying Chytrid Biology and Evolutionary Cell Biology.” ELife 11(9):e52741.

Metchnikoff, Elie. 1886. Embryologische Studien an Medusen : Ein Beitrag Zur Genealogie Der Primitiv-Organe. Vienna: A. Hölder.

Mikhailov, Kirill V., Anastasiya V. Konstantinova, Mikhail A. Nikitin, Peter V. Troshin, Leonid Yu Rusin, Vassily A. Lyubetsky, Yuri V. Panchin, Alexander P. Mylnikov, Leonid L. Moroz, Sudhir Kumar, and Vladimir V. Aleoshin. 2009. "The Origin of Metazoa: A Transition from Temporal to Spatial Cell Differentiation." BioEssays 31(7):758-68.

Miller, Stephen A. and John P. Harley. 1999. Zoology. 4th ed. Boston: McGraw-Hill Book Company.

Mitchell, Lawrence A., John A. Mulmor, and Warren D. Dolphin. 1988. Zoology. Menlo Park, California: The Benjamin/Cummings Publishing Company.

Morange, Michel. 2016. Une Histoire de La Biologie. Editions du Seuil.

Müller, O. F. 1786. Animalcula Infusoria Fluviatilia et Marina Quae Detexit, Systematice Descripsit et Ad Vivum Delineari Curavit. Mölleri.

Myers, Paul Z. 2019. “Actually, I Fail to See a Single Thing in This Paper That Would Require Any Textbook Rewriting at All." Pharyngula. Retrieved (https://freethoughtblogs.com/pharyngula/2019/06/13/actually-i-failto-see-a-single-thing-in-this-paper-that-would-require-any-textbook-rewriting-at-all/).

Nakanishi, Nagayasu, Shunsuke Sogabe, and Bernard M. Degnan. 2014. "Evolutionary Origin of Gastrulation: Insights from Sponge Development.” BMC Biology 12:26.

Nerrevang, A. and K. G. Wingstrand. 1970. "On the Occurrence and Structure of Choanocyte-like Cells in Some Echinoderms." Acta Zoologica 51(3):249-70.

Nichols, Scott A., Mark J. Dayel, and Nicole King. 2009. "Genomic, Phylogenetic, and Cell Biological Insights into Metazoan Origins." in Animal Evolution: Genomes, Fossils, and Trees.

Nielsen, Claus. 2008. “Six Major Steps in Animal Evolution: Are We Derived Sponge Larvae?" Evolution and Development 10(2):241-57.

Nielsen, Claus. 2012. Animal Evolution. Interrelationships of the Living Phyla. 3rd ed. Oxford University Press.

Nielsen, Claus and Arne Norrevang. 1985. "The Trochaea Theory: An Example of Life Cycle Phylogeny.” Pp. 2841 in The Origins and Relationships of Lower Invertebrates, edited by S. Conway Morris, J. D. George, R. 
Gibson, and H. M. Platt. Oxford: Clarendon Press.

Parra-Acero, Helena, Matija Harcet, Núria Sánchez-Pons, Elena Casacuberta, Nicholas H. Brown, Omaya Dudin, and Iñaki Ruiz-Trillo. 2020. "Integrin-Mediated Adhesion in the Unicellular Holozoan Capsaspora Owczarzaki." Current Biology 30(21):4270-75.

Parra-Acero, Helena, Núria Ros-Rocher, Alberto Perez-Posada, Aleksandra Kożyczkowska, Núria Sánchez-Pons, Azusa Nakata, Hiroshi Suga, Sebastián R. Najle, and Iñaki Ruiz-Trillo. 2018. "Transfection of Capsaspora Owczarzaki, a Close Unicellular Relative of Animals.” Development (Cambridge) 145(10):dev162107.

Pedersen, Knud Jørgen. 1964. “The Cellular Organization of Convoluta Convoluta, an Acoel Turbellarian: A Cytological, Histochemical and Fine Structural Study." Zeitschrift Für Zellforschung Und Mikroskopische Anatomie 20(64):655-87.

Pennisi, E. 1997. “Haeckel’s Embryos: Fraud Rediscovered.” Science 277(5331):1435.

Pflug, H. D. 1974. "Vor- Und Fruh-Geschichte Der Metazoen.” N. Jahrb. Geol. Palaeont. Abh. 145:328-74.

Reutterer, Alois. 1969. “Zum Problem Der Metazoenabstammung.” Z. Zool. Syst. Evol. 7:30-53.

Reynolds, Andrew and Norbert Hülsmann. 2008. "Ernst Haeckel's Discovery of Magosphaera Planula: A Vestige of Metazoan Origins?" History and Philosophy of the Life Sciences 30(3-4):339-86.

Richards, Robert J. 2008. The Tragic Sense of Life: Ernst Haeckel and the Struggle over Evolutionary Thought. University of Chicago Press.

Richards, Robert J. 2009. “Haeckel's Embryos: Fraud Not Proven.” Biology \& Philosophy (24):147-54.

Richter, Daniel J., Parinaz Fozouni, Michael B. Eisen, and Nicole King. 2018. "Gene Family Innovation, Conservation and Loss on the Animal Stem Lineage" edited by M. J. Telford. ELife 7:e34226.

Rieger, R. M. 1976. "Monociliated Epidermal Cells in Gastrotricha: Significance for Concepts of Early Metazoan Evolution.” Journal of Zoological Systematics and Evolutionary Research 14(3):198-226.

Rokas, Antonis, Nicole King, John Finnerty, and Sean B. Carroll. 2003. "Conflicting Phylogenetic Signals at the Base of the Metazoan Tree.” Evolution and Development 5(4):346-59.

Ruiz-Trillo, Iñaki, Andrew J. Roger, Gertraud Burger, Michael W. Gray, and B. Franz Lang. 2008. “A Phylogenomic Investigation into the Origin of Metazoa.” Molecular Biology and Evolution 25(4):664-72.

Rundell, Rebecca J. and Brian S. Leander. 2010. "Masters of Miniaturization: Convergent Evolution among Interstitial Eukaryotes.” BioEssays 32(5):430-37.

Sachwatkin, A. A. 1956. Vergleichende Embryologie Der Niederen Wirbellosen: Ursprung Und Gestaltungswege Der Individuellen Entwicklung Der Vielzeller. Berlin: VEB Deutscher Verlag der Wissenschaften.

Salvini-Plawen, Luitfried V. 1978. "On the Origin and Evolution of the Lower Metazoa.” Journal of Zoological Systematics and Evolutionary Research 16(1):40-88.

Schardinger, F. 1899. "Entwicklungskreis Einer Amoeba Lobosa (Gymnamoeba): Amoeba Gruberi. Sitzb Kaiserl." Akad. Wiss. Wien Abt. 1:713-734.

Schleiden, Matthias. 1839. "Beiträge Zur Phytogenesis.” Archiv Für Anatomie, Physiologie Und Wissenschaftliche Medicin 1838:137-176.

Schloegel, Judy Johns and Henning Schmidgen. 2002. “General Physiology, Experimental Psychology, and Evolutionism. Unicellular Organisms as Objects of Psychophysiological Research, 1877-1918.” Isis 93:61445 .

Schwann, Theodor. 1839. Mikroskopische Untersuchungen Über Die Uebereinstimmung in Der Struktur Und Dem Wachsthum Der Thiere Und Pflanzen. Berlin: Sander.

Sebé-Pedrós, Arnau, Cecilia Ballaré, Helena Parra-Acero, Cristina Chiva, Juan J. Tena, Eduard Sabidó, José Luis Gómez-Skarmeta, Luciano Di Croce, and Iñaki Ruiz-Trillo. 2016. “The Dynamic Regulatory Genome of Capsaspora and the Origin of Animal Multicellularity." Cell 165(5):1224-37. 
Sebé-Pedrós, Arnau, Bernard M. Degnan, and Iñaki Ruiz-Trillo. 2017. "The Origin of Metazoa: A Unicellular Perspective." Nature Reviews Genetics 18(8):498-512.

Sebé-Pedrós, Arnau, Xavier Grau-Bové, Thomas A. Richards, and Iñaki Ruiz-Trillo. 2014. "Evolution and Classification of Myosins, a Paneukaryotic Whole-Genome Approach." Genome Biology and Evolution 6(2):290-305.

Sebé-Pedrós, Arnau, Manuel Irimia, Javier del Campo, Helena Parra-Acero, Carsten Russ, Chad Nusbaum, Benjamin J. Blencowe, and Iñaki Ruiz-Trillo. 2013. "Regulated Aggregative Multicellularity in a Close Unicellular Relative of Metazoa.” ELife 24(2):e01287.

Sebé-Pedrós, Arnau, Marcia Ivonne Peña, Salvador Capella-Gutiérrez, Meritxell Antó, Toni Gabaldón, Iñaki RuizTrillo, and Eduard Sabidó. 2016. "High-Throughput Proteomics Reveals the Unicellular Roots of Animal Phosphosignaling and Cell Differentiation.” Developmental Cell 39(2):186-97.

Sedgwick, Adam. 1895. "Memoirs: Further Remarks on the Cell-Theory, with a Reply to Mr. Bourne." Journal of Cell Science 38:331-37.

Sogabe, Shunsuke, William L. Hatleberg, Kevin M. Kocot, Tahsha E. Say, Daniel Stoupin, Kathrein E. Roper, Selene L. Fernandez-Valverde, Sandie M. Degnan, and Bernard M. Degnan. 2019. "Pluripotency and the Origin of Animal Multicellularity." Nature 570(7662):519-22.

Steinböck, Otto. 1963. "Origin and Affinities of the Lower Metazoa: The 'Acoeloid' Ancestry of the Eumetazoa." Pp. 45-54 in The Lower Metazoa, edited by E. C. Dougherty, Z. N. Brown, E. D. Hanson, and W. D. Hartman. University of California Press, Berkeley.

Suga, Hiroshi, Zehua Chen, Alex De Mendoza, Arnau Sebé-Pedrós, Matthew W. Brown, Eric Kramer, Martin Carr, Pierre Kerner, Michel Vervoort, Núria Sánchez-Pons, Guifré Torruella, Romain Derelle, Gerard Manning, B. Franz Lang, Carsten Russ, Brian J. Haas, Andrew J. Roger, Chad Nusbaum, and Iñaki Ruiz-Trillo. 2013. "The Capsaspora Genome Reveals a Complex Unicellular Prehistory of Animals." Nature Communications 4:2325.

Suga, Hiroshi and Iñaki Ruiz-Trillo. 2013. "Development of Ichthyosporeans Sheds Light on the Origin of Metazoan Multicellularity.” Developmental Biology 377(1):284-92.

Tikhonenkov, Denis V., Elisabeth Hehenberger, Anton S. Esaulov, Olga I. Belyakova, Yuri A. Mazei, Alexander P. Mylnikov, and Patrick J. Keeling. 2020. "Insights into the Origin of Metazoan Multicellularity from Predatory Unicellular Relatives of Animals.” BMC Biology 18(1):39.

Tikhonenkov, Denis V., Kirill V. Mikhailov, Elisabeth Hehenberger, Sergei A. Karpov, Kristina I. Prokina, Anton S. Esaulov, Olga I. Belyakova, Yuri A. Mazei, Alexander P. Mylnikov, Vladimir V. Aleoshin, and Patrick J. Keeling. 2020. "New Lineage of Microbial Predators Adds Complexity to Reconstructing the Evolutionary Origin of Animals." Current Biology.

Wainright, Patricia O., Gregory Hinkle, Mitchell L. Sogin, and Shawn K. Stickel. 1993. "Monophyletic Origins of the Metazoa: An Evolutionary Link with Fungi." Science 260(5106):340-42.

Wan, Kirsty and Gáspár Jékely. 2020. “Origins of Eukaryotic Excitability.” ArXiv.

Willmer, E. N. 1971. Cytology and Evolution. 2nd ed. Academic Press.

Willmer, Pat. 1990. Invertebrate Relationships. Cambridge University Press.

Wilson, H. V. 1887. "Metschnikoff on Germ-Layers.” The American Naturalist 21(4):334-50.

Zakhvatkin, Alexey. 1949. The Comparative Embryology of the Low Invertebrates. Sources and Method of the Origin of Metazoan Development. Moscow: Soviet Science. 